\title{
INFRA-RED SPECTRA OF 1:10-PHENANTHROLINE METAL COMPLEXES IN THE ROCK SALT REGION BELOW $2000 \mathrm{~cm}^{-1}$
}

\author{
A. A. Schilt and R. C. TAYloR \\ Department of Chemistry, The University of Michigan, \\ Ann Arbor, Michi_an
}

(Received 9 September 1958)

\begin{abstract}
Infra-red spectra of twenty two metal-1:10-phenanthroline perchlorates together with spectra of the free ligand, its hydrate and perchlorate salt have been obtained in the region between 600 and $2000 \mathrm{~cm}^{-1}$ from Nujol mulls. In general, the spectra of the complexes were remarkably similar in their gross features and no obvious correlations with magnetic or other physical properties were noted. However, the results provide evidence for co-ordination in the case of the alkali metal complexes and also indicate a co-ordination number of eight in the alkaline earth, lead and manganese complexes. The compositions of all compounds studied were confirmed by elementary microanalysis and the list includes several new compounds as well as a few having compositions differing slightly from those previously reported. The interpretation of the principal features of the spectra is discussed.
\end{abstract}

Although an increasing number of papers reporting on the infra-red spectra of metal co-ordination complexes have appeared in the recent literature, the results available are not yet adequate for a proper assessment of this technique's value, apart from its usefulness in characterization and identification. Most of the studies which have appeared to date have dealt with complexes involving either very simple ligands such as $\mathrm{NH}_{3}$ or $\mathrm{CN}^{-},{ }^{(1-4)}$ or with ligands having a co-ordinating group which can be associated with a characteristic vibration frequency such as $\beta$-diketones ${ }^{(5)}$ or compounds containing $-\mathrm{COOH}$ or $-\mathrm{NH}_{2}$ groups. ${ }^{(6-8)}$ Very few data have been presented for compounds where the complexing agent is a fairly large and complicated molecule. In general, more or less marked alterations in the spectrum of the ligand have been reported to occur upon co-ordination, and in some cases it has been possible to interpret these changes satisfactorily in terms of the structure or geometry of the complex, or to relate them to changes in bonding in the ligand. It has also been found that these changes in the ligand spectrum are relatively insensitive to the nature of the metal involved such that disappointingly little has been learned about the metal to ligand bond.

In the present work, the infra-red spectra of a number of heavy metal complexes with 1:10-phenanthroline have been obtained together with the spectra of several alkali and alkaline earth complexes, acid salts and the hydrate. For comparison purposes, the spectra of a small number of 2:2-bipyridine complexes were also

(1) D. B. Powell and N. Sheppard, J. Chem. Soc, 3108 (1956).

(2) G. M. Barrow, R. H. Krueger and F. Basolo, J. Inorg. Nucl. Chem. 2, 340 (1956).

(3) L. H. Jones, J. Chem. Phys. 26, 1578 (1956); 27, 468, 665 (1957).

(4) G. F. Svatos, D. M. Sweeny, S. Mizushima, C. Curran and J. V. Quagliano, J. Amer. Chem. Soc. 79, 3313 (1957).

(5) H. F. Holtzclaw and J. P. Collman, J. Amer. Chem. Soc. 79, 3318 (1957).

(6) M. L. MORris and D. H. Busch, J. Amer. Chem. Soc. 78, 5178 (1956).

(7) R. B. Penland, S. Mizushima, C. Curran and J. V. Quagliano, J. Amer. Chem. Soc. 79, 1575 (1957).

(8) K. Nakamoto, J. Fujita, S. Tanaka and M. Kobayashi, J. Amer. Chem. Soc. 79, 4904 (1957). 
obtained. The anion present in all cases was perchlorate which was selected because it gave nicely crystalline salts which could be easily handled. Since many complexes of 1:10-phenanthroline have not been completely characterized, or doubtful points are present in the literature preparations, all compounds were subjected to elemental microanalysis before their spectra were accepted. In several cases, the compositions determined by the analytical data represented new compounds or minor variations from the compounds previously reported.

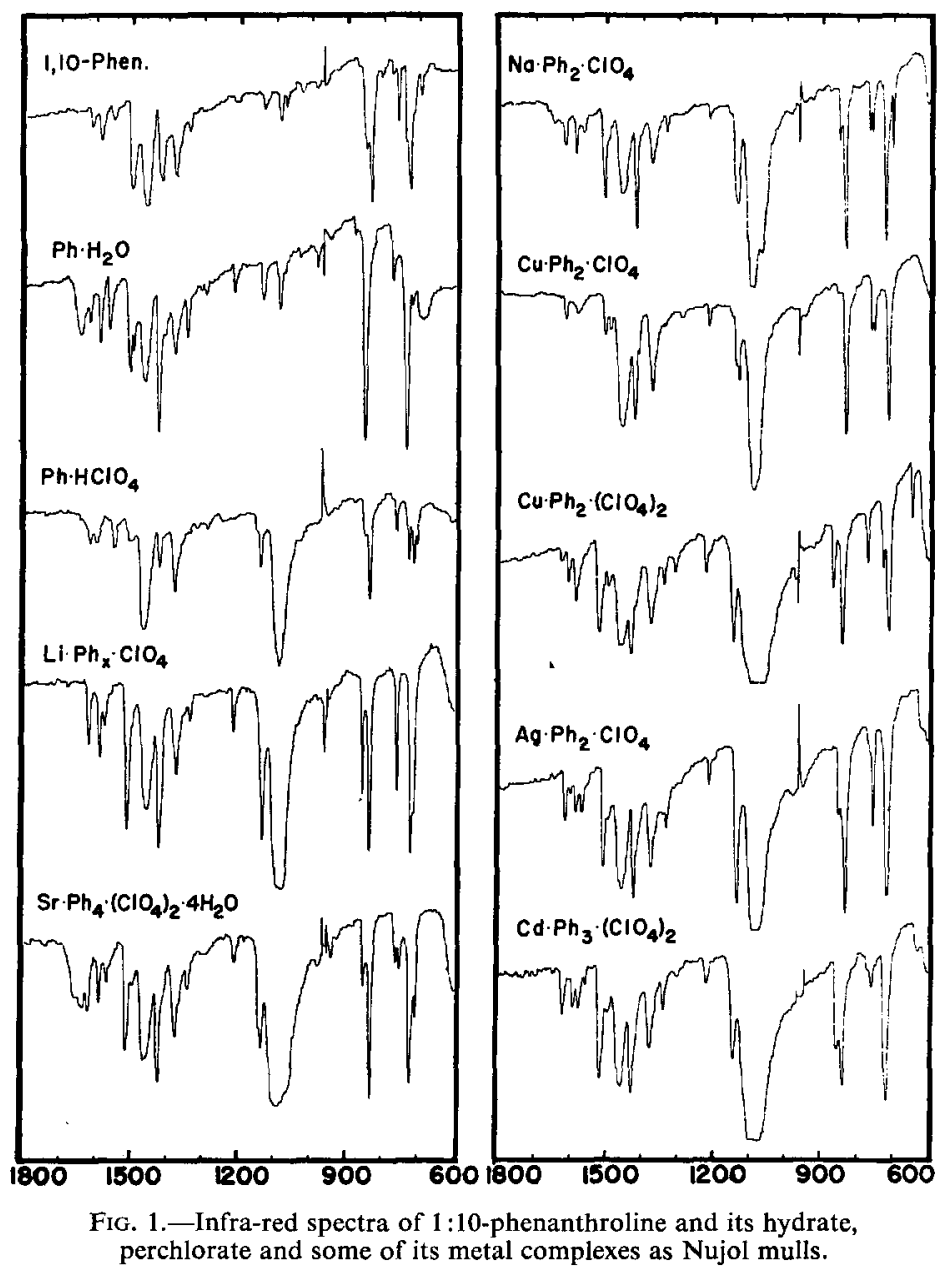

The spectral results are of interest in connexion with questions regarding the metal co-ordination number in certain complexes and also provide a limited amount of information regarding bonding in the complexes.

\section{EXPERIMENTAL RESULTS}

Spectra of the 1:10-phenanthroline metal complexes, the spectrum of the free base, its hydrate and perchlorate salt are shown in Figs. 1-3 while the measured frequencies of the band maxima are given in Table 1. Similar information for the bipyridine complexes is given in Table 2 and selected spectra are shown in Fig. 3. 
Inspection of the results shows that in their gross features, the spectra of the various phenanthroline complexes are remarkably similar in appearance and show no obvious correlations either with magnetic or other physical properties of the complexes, with the valence of the metal or with the number of ligand groups co-ordinated. Since the vibrational frequencies observed in the rock salt region arise exclusively in the ligand part of the complex, which, in this case, is fairly large and complex, it is perhaps not surprising that the spectra do not vary markedly from metal to metal.

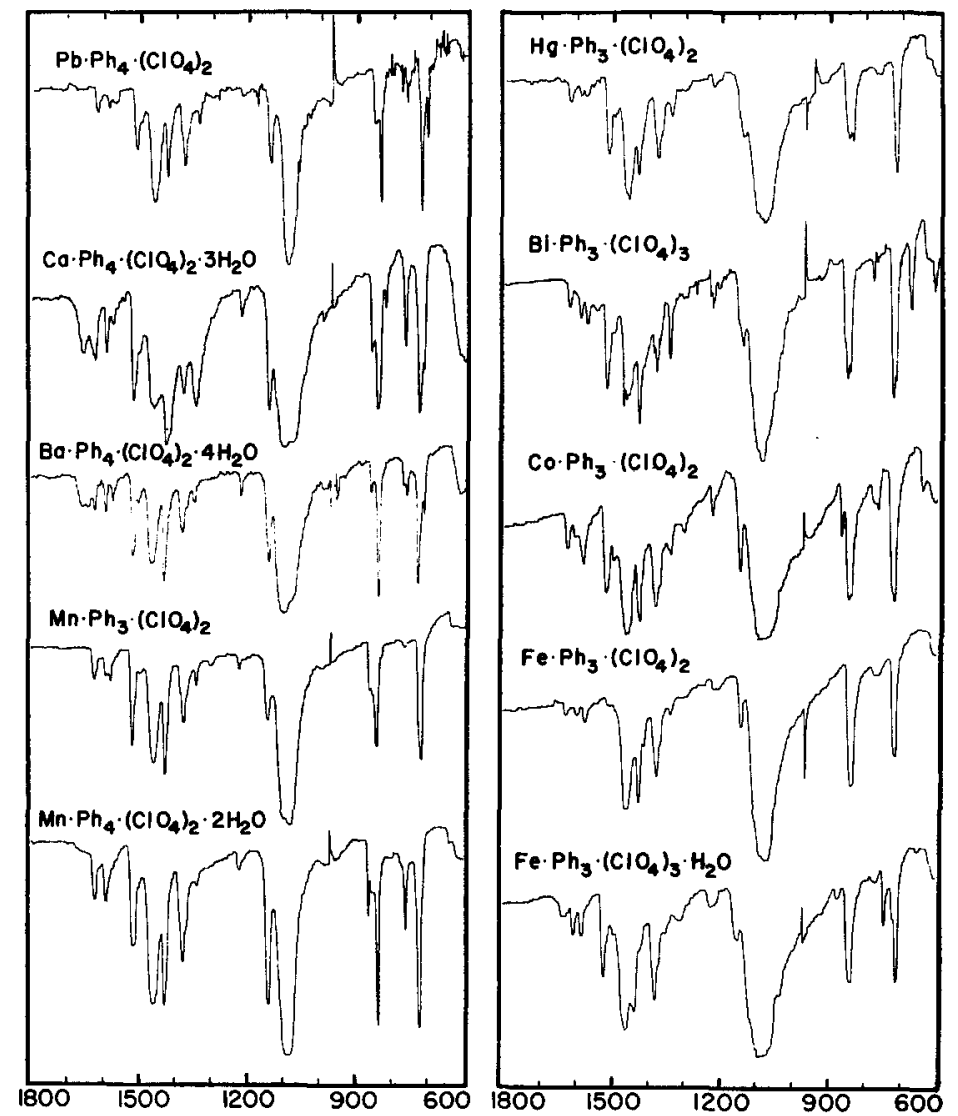

FIG. 2.-Infra-red spectra of some metal complexes of $1: 10$-phenanthroline from Nujol mulls.

Similar observations have been made elsewhere in studies involving simpler ligands.

More detailed examination of the spectra shows that the metal complexes are easily distinguishable from either the free base, the hydrate or the acid salt and this provides a satisfactory method of detecting the presence of occluded or uncomplexed ligand. For example, phenanthroline perchlorate can be identified in mixtures by a strong band at $1544 \mathrm{~cm}^{-1}$ since the corresponding band in the metal complexes is confined to the range between 1510 and $1530 \mathrm{~cm}^{-1}$. Several other acid salts were also examined in the course of this investigation including the chloride, bromide, nitrate and sulphate. In all cases the band mentioned fell consistently outside the range of the same band in the metal complexes. Differentiation of the free base or the hydrate from the metal complexes requires more careful comparison since no single band 


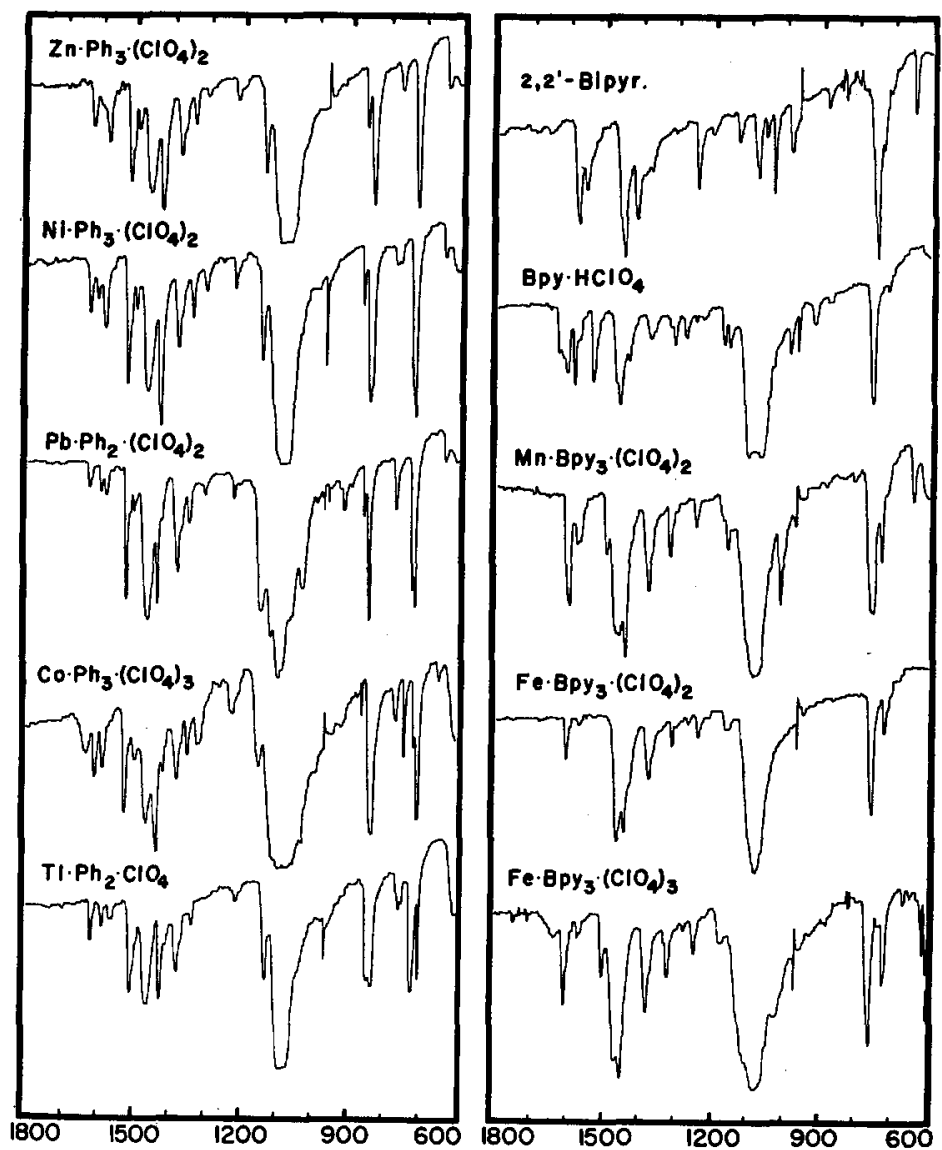

FIG. 3.-Infra-red spectra of some metal complexes of $1: 10$-phenanthroline and $2: 2^{\prime}$-bipyridine from Nujol mulls.

can be selected which will give an unequivocal answer as in the case of the acid salts. Detailed comparison of the bands in the $700-900 \mathrm{~cm}^{-1}$ region appears most suitable.

The spectra of the metal complexes themselves differed in minor respects such that no two were identical, although the cobalt and nickel were nearly so. Principal differences occurred in the $700-900 \mathrm{~cm}^{-1}$ region and consisted of varied patterns in the splitting of the strong bands near 720 and $850 \mathrm{~cm}^{-1}$.

The results for the $\mathrm{Li}, \mathrm{Na}$ and alkaline earth complexes are of some interest in view of questions raised ${ }^{(9)}$ as to whether the alkali metals actually are chelated in the complexes, and in regard to the high co-ordination number observed for the alkaline earths. Since experimental limitations prevented study of the spectral region in which frequencies associated with the metal-nitrogen bond might be expected, the evidence bearing on these two questions is somewhat indirect. However, in the case of the heavy transition metal complexes, certain modifications of the spectrum of the free ligand occurred which appear to be characteristic of the ligand in the bound state. Perhaps the most obvious of the alterations was a general shift of the ring vibrations in the $1400-1600 \mathrm{~cm}^{-1}$ region to higher frequency. These modifications were clearly present

(日) W. W. Brandt, F. P. Dwyer and E. C. Gyarfas, Chem. Rev. 54, 959 (1954). 


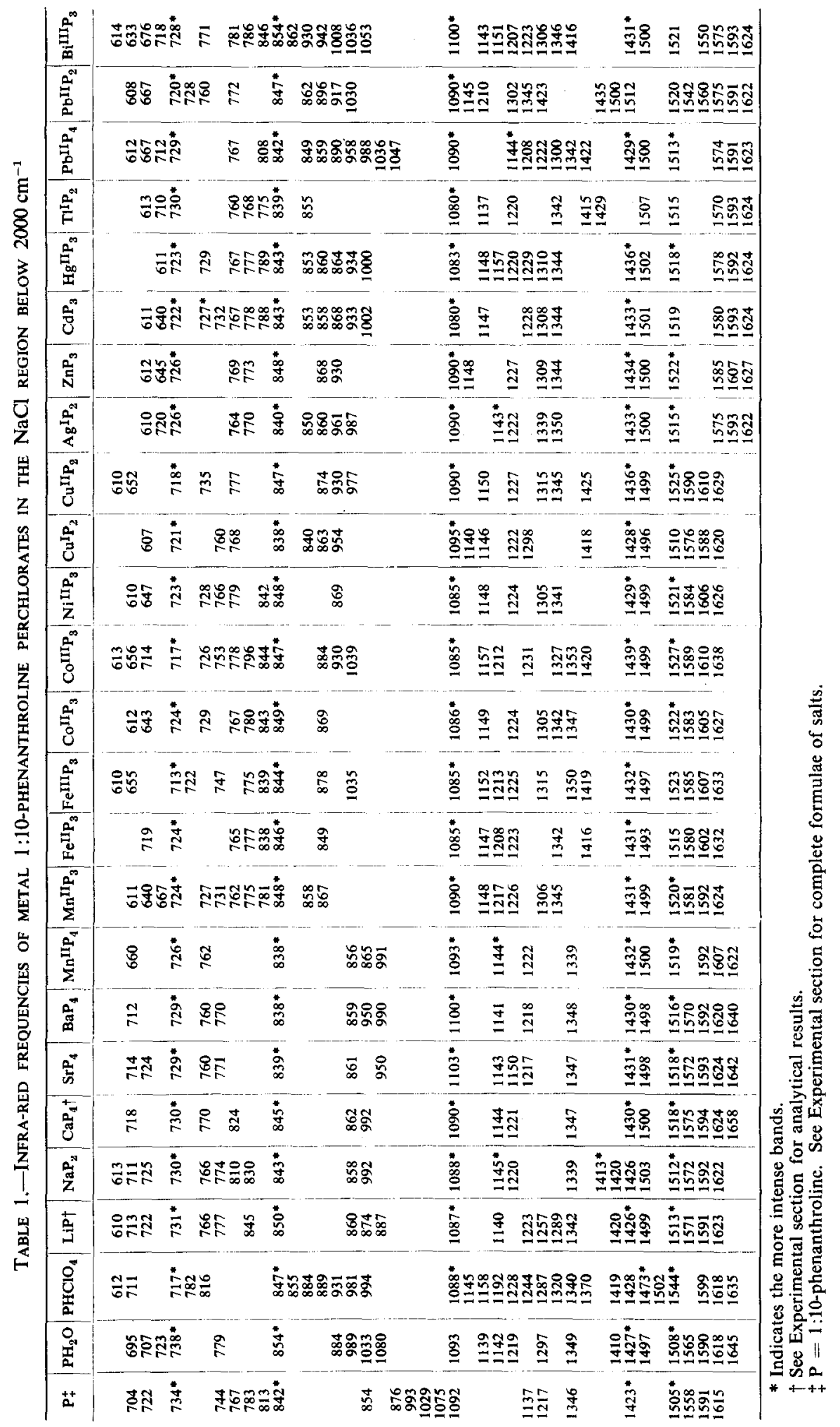


TABLE 2.-INFRA-RED FREQUENCIES OF SOME METAL 2:2'-BIPYRIDINE PERCHLORATES IN THE NaCl REGION BELOW $2000 \mathrm{~cm}^{-1}$

\begin{tabular}{|c|c|c|c|c|c|c|c|}
\hline $\mathbf{B} \dagger$ & $\mathrm{BHClO}_{4}$ & $\mathrm{Mn}^{\mathrm{II}} \mathrm{B}_{3}$ & $\mathrm{Fe}^{\mathrm{II}} \mathrm{B}_{3}$ & $\mathrm{Fe}^{\mathrm{III}} \mathrm{B}_{3}$ & $\mathrm{Co}^{\mathrm{II}} \mathrm{B}_{3}$ & $\mathrm{Co}^{\mathrm{III}_{\mathrm{B}_{3}}}$ & $\mathrm{Ni}^{\mathrm{in}^{\mathrm{I}}} \mathrm{B}_{3}$ \\
\hline \multirow[t]{2}{*}{652} & & 650 & & 669 & 652 & & 650 \\
\hline & 722 & 720 & 720 & 722 & & 720 & 717 \\
\hline 739 & & 736 & 728 & $\begin{array}{l}726 \\
741\end{array}$ & 735 & 724 & 732 \\
\hline \multirow[t]{2}{*}{$755^{*}$} & $763^{*}$ & $762^{*}$ & $763^{*}$ & $764^{*}$ & $766^{*}$ & $763^{*}$ & $763^{*}$ \\
\hline & & 767 & 768 & 797 & 774 & 792 & 771 \\
\hline \multirow[t]{2}{*}{892} & 888 & 810 & & 889 & 889 & 889 & 886 \\
\hline & 926 & & 954 & 932 & & & 927 \\
\hline \multirow{2}{*}{992} & 994 & 973 & 997 & & 964 & & 961 \\
\hline & 1020 & & & 1020 & 1021 & & 1005 \\
\hline \multirow{3}{*}{$\begin{array}{l}1041 \\
1065\end{array}$} & 1042 & 1007 & & 1030 & 1045 & 1036 & 1016 \\
\hline & 1050 & & & & & & 1021 \\
\hline & & $\begin{array}{l}1018 \\
1045\end{array}$ & 1070 & & 1072 & & \\
\hline \multirow{2}{*}{$\begin{array}{l}1085 \\
1090\end{array}$} & $1070 *$ & $1088^{*}$ & $1084^{*}$ & $1080^{*}$ & $1085^{*}$ & $1088^{*}$ & $1083^{*}$ \\
\hline & 1112 & & & & & & \\
\hline \multirow[t]{2}{*}{1140} & 1161 & 1161 & 1160 & 1170 & 1158 & 1166 & 1156 \\
\hline & $\begin{array}{l}1177 \\
1234\end{array}$ & 1175 & 1167 & 1180 & $\begin{array}{l}1172 \\
1218\end{array}$ & 1177 & $\begin{array}{l}1169 \\
1217\end{array}$ \\
\hline \multirow[t]{4}{*}{1252} & 1253 & 1247 & 1242 & 1247 & 1248 & 1246 & 1246 \\
\hline & 1281 & & 1272 & 1278 & & & \\
\hline & 1312 & & 1315 & & 1317 & & 1313 \\
\hline & 1324 & 1320 & & $\begin{array}{l}1321 \\
1370\end{array}$ & & 1320 & \\
\hline \multirow[t]{2}{*}{$1421^{*}$} & 1370 & $1446^{*}$ & $1448^{*}$ & $1456^{*}$ & $\begin{array}{l}1446^{*} \\
1474\end{array}$ & $1455^{*}$ & $1445^{*}$ \\
\hline & $1537^{*}$ & 1496 & & 1503 & 1498 & 1505 & 1496 \\
\hline \multirow{5}{*}{$\begin{array}{l}1560 \\
1583^{*}\end{array}$} & 1576 & 1570 & 1569 & 1567 & 1566 & 1570 & 1564 \\
\hline & 1589 & 1576 & & & 1576 & & 1574 \\
\hline & 1610 & $1601^{*}$ & 1607 & 1608 & $1604^{*}$ & 1609 & $1603^{*}$ \\
\hline & 1622 & & & 1630 & & & \\
\hline & 1633 & 1608 & & & & & \\
\hline
\end{tabular}

* Indicates the more intense bands.

$\dagger \mathrm{B}=2: 2^{\prime}$-bipyridine. See Experimental section for complete formulae of salts.

in both the lithium and sodium complexes as well as those of the alkaline earths, although the magnitude of the shifts was not as great as for the heavy metals. Since no bands attributable to the free base or its hydrate were observed, one is led to conclude that all the phenanthroline present in these light metal complexes is co-ordinated. This conclusion is supported by the observation that no ligand was lost when the compounds were heated in vacuo at $110^{\circ} \mathrm{C}$. The analytical data confirm the presence of four (bidentate) ligands in the strontium and barium complexes and between three and four for calcium. Similarly, the spectral and analytical data support a co-ordination number of eight for manganese(II) and lead(II) in their tetrakis complexes. 
However, the spectra of literature preparations with tin(II) give no evidence of coordination and showed only the lines of phenanthroline perchlorate.

Co-ordination involving protons, either in water or from an acid, produced the same characteristic shifts as co-ordination to a metal. In the case of water, the magnitude of the effects was small, smaller even than for the alkali and alkaline earth metals, but in the salts of strong acids where the proton is bound firmly to the nitrogen atom, the shifts were quite striking.

\section{DISCUSSION OF THE SPECTRAL RESULTS}

No general, systematic study of the vibrational frequencies of heterocyclic aromatic compounds has appeared in the literature and even the spectra of polycyclic aromatic hydrocarbons have not been dealt with at all extensively. BELlamy, ${ }^{(10)}$ and Jones and SANDORFY(11) however, indicate that many of the generalizations based on studies of benzene derivatives may be carried over quite successfully to polycyclic molecules and that the introduction of a heteroatom into a ring usually results in only minor changes in the characteristic skeletal frequencies of the corresponding hydrocarbon. In its effect on the frequencies associated with the hydrogen atoms attached to the ring, the heteroatom behaves as a substituted carbon atom.

In the spectra of the phenanthroline complexes between 600 and $2000 \mathrm{~cm}^{-1}$, strong bands were observed in three frequency regions, namely between 700 and 900 $\mathrm{cm}^{-1}$, between 1125 and $1250 \mathrm{~cm}^{-1}$, and between 1400 and $1650 \mathrm{~cm}^{-1}$. Nujol bands prevented observation of bands in the neighbourhood of 1380 and $1465 \mathrm{~cm}^{-1}$ while a very intense band due to the perchlorate anion obliterated frequencies due to the ligand in a region about $70 \mathrm{~cm}^{-1}$ wide centered around $1085 \mathrm{~cm}^{-1}$. Strong bands in the $700-900 \mathrm{~cm}^{-1}$ region in spectra of aromatic hydrocarbons have been identified with motions of ring hydrogen atoms moving in phase out of the plane of the ring. The particular frequency at which such bands appear further has been shown to depend on the number of adjacent hydrogen atoms around the ring and has been used to determine substitution patterns. In phenanthroline, and also its complexes, two strong bands appeared at approximately 725 and $850 \mathrm{~cm}^{-1}$. This is the number expected since there is one group of two and two groups of three adjacent hydrogen atoms in the ring system. In hydrocarbons, the frequency shifts upwards as the number of adjacent atoms in a group decreases. On this basis, the $725 \mathrm{~cm}^{-1}$ band is assigned to the out of plane motion of the hydrogen atoms on the heterocyclic rings and the $850 \mathrm{~cm}^{-1}$ band to the hydrogens on the centre ring. The multiple splittings which these bands exhibited in most of the spectra probably arise from out-of-plane hydrogen motions other than the one in which all atoms move in phase, and also possibly from overtones of low lying fundamentals in resonance. In the bipyridyl spectra, only one strong band was observed in this region as expected for two identical groups of four hydrogen atoms each. The pattern of splitting of all these bands appeared quite sensitive to small differences in the nature of the co-ordinated atom since this region of the spectrum was most characteristic of any given complex. The variations did not appear systematic however.

Not much can be said about the bands in the $1125-1250 \mathrm{~cm}^{-1}$ region except that

(10) L. J. Bellamy, The Infra-red Spectra of Complex Molecules. John Wiley, New York (1954).

(11) R. N. Jones and C. SANDORFY, Chemical Applications of Spectroscopy, Vol. IX, Technique of Organic Chemistry Chap. V. Interscience Publishers, New York (1956). 
they may arise from in-plane hydrogen deformation motions or possibly ring vibrations. Even in the case of many simple aromatic compounds, satisfactory assignments for bands in this part of the spectrum are not available. The observed positions of the bands in the complexes varied somewhat from metal to metal but the shifts were scarcely large enough to justify any attempts at correlations.

It is in the third region that characteristic ring frequencies of aromatic compounds occur, both in monocyclic and polycyclic compounds and in heterocyclic as well as

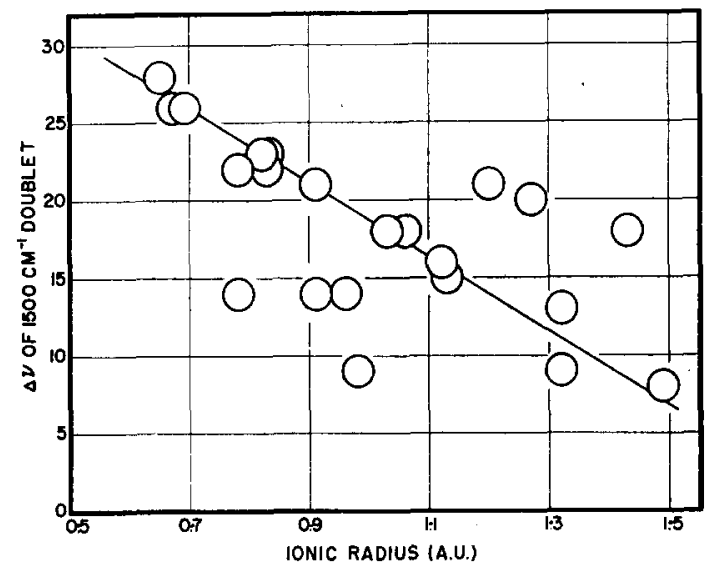

FIG. 4.-Separation between the two components of the $1500 \mathrm{~cm}^{-1}$ doublet vs. the ionic radius of the metal ion in $1: 10$-phenanthroline complexes.

carbocyclic. Perhaps the most typical and usually the most intense of these ring frequencies are one close to $1500 \mathrm{~cm}^{-1}$ and a second in the neighbourhood of 1600 $\mathrm{cm}^{-1}$, the latter often consisting of more than one maximum. For example, in phenanthrene the first occurs ${ }^{(12)}$ at approximately $1500 \mathrm{~cm}^{-1}$ and the second at about 1605 $\mathrm{cm}^{-1}$ with a second component some $25 \mathrm{~cm}^{-1}$ or so higher. A third strong band occurs at about $1450 \mathrm{~cm}^{-1}$. The spectrum of $1: 10$-phenanthroline is quite similar, the one band occurring at $1505 \mathrm{~cm}^{-1}$, the second appearing as a triplet with the centre component at $1590 \mathrm{~cm}^{-1}$ and the third band shifting to $1423 \mathrm{~cm}^{-1}$. Reference has been made previously to the fact that all these bands move to higher frequencies on coordination. The $1423 \mathrm{~cm}^{-1}$ band was least sensitive in this respect but the other two showed a clearly discernable shift of the order of 10 to $25 \mathrm{~cm}^{-1}$. In addition, in all the complex spectra observed, the $1505 \mathrm{~cm}^{-1}$ band exhibited a weak satellite on its low frequency side. In some of the spectra, this component was present as a shoulder but in most it appeared as a sharp and well defined, though weak, band. The separation of the two maxima varied from metal to metal and several correlations with various properties of the metal ion were tried. It was found that the splitting varied in a direct manner with the ionic radius of the metal ion although the relationship was not as striking as one might wish since the magnitude of the separation did not exceed $30 \mathrm{~cm}^{-1}$ in any one case. The correlation is shown in Fig. 4. Similar, though not quite as good, correlations with the ionic radius were also noted for the mean position of the triplet at $1600 \mathrm{~cm}^{-1}$, and for the separation between the 725 and $850 \mathrm{~cm}^{-1}$ bands. (12) C. G. Cannon and G. B. B. M. Sutherland, Spectrochim. Acta 4, 373 (1951). 
These observations suggest that the size and consequent polarizing effect of the metal ion exercises a small but observable influence on the distribution of the electrons in the ring system. Co-ordination of the phenanthroline to a proton instead of to a metal ion resulted in a significantly greater splitting of the $1500 \mathrm{~cm}^{-1}$ band and also greater shifts of the other bands. Since the proton has a much small size and consequently a greater polarizing effect, the electrostatic picture is consistent.

The spectra of $2: 2^{\prime}$-bipyridine and its complexes in general were less complicated than those of phenanthroline. Only three strong bands were present, one near 760 $\mathrm{cm}^{-1}$ ascribed to out of plane bending of ring hydrogens as mentioned previously, one near $1450 \mathrm{~cm}^{-1}$ which is probably a ring frequency, and a ring frequency near $1600 \mathrm{~cm}^{-1}$. Numerous weak bands were observed between 900 and $1300 \mathrm{~cm}^{-1}$. No close similarity to the phenanthroline spectra was noted except for the two ring frequencies. The absence of a strong band near $1500 \mathrm{~cm}^{-1}$ suggests that this particular ring frequency in the phenanthroline compounds is associated with the carbocyclic ring. No correlations with properties of the metal were apparent although the small number of complexes examined made attempts difficult.

\section{EXPERIMENTAL}

Spectroscopic. The infra-red absorption spectra were obtained with a Perkin-Elmer Model 21 spectrometer equipped with $\mathrm{NaCl}$ optics. All substances were examined as Nujol mulls. The frequencies tabulated for the various bands are considered to have an uncertainty of $\pm 5 \mathrm{~cm}^{-1}$ below $1800 \mathrm{~cm}^{-1}$ while the reproducibility generally was $\pm 1 \mathrm{~cm}^{-1}$ on the sharp bands and $\pm 2 \mathrm{~cm}^{-1}$ on most of the rest. Due to the presence of Nujol bands, the hydrogen stretching region yielded little information except to confirm the existence of a hydrate where it existed.

Analytical. All compounds were analysed for nitrogen and, wherever practicable, for metal content and carbon and hydrogen.* Since most of the compounds undergo violent decomposition on heating, melting points were not determined. The 1:10-phenanthroline monohydrate and 2:2'bipyridine were obtained from the G. Frederick Smith Chemical Co. and used without further purification.

1:10-Phenanthroline. The anhydrous material was obtained on drying the monohydrate in vacuo at $110^{\circ} \mathrm{C}$ over phosphorous pentoxide.

1:10-Phenanthrolium perchlorate. The salt was isolated as an amorphous precipitate after adding a slight excess of perchloric acid to an aqueous solution of the free base. Recrystallization from water converted the product into glistening white needles. (Found: C, 51.2; H, 3.15; N, 9.94. Calc. for Phen. $\mathrm{HClO}_{4}$ : C, $51 \cdot 4 ; \mathrm{H}, 3 \cdot 21 ; \mathrm{N}, 9.97 \%$ ).

Lithium complex. Attempts to isolate a lithium complex of definite composition following the procedure reported by PFEIFFER and CHRISTELEIT ${ }^{(13)}$ for the preparation of mono-(1,10-phenanthroline)lithium(I) perchlorate were unsuccessful. The products obtained most likely were mixtures of complexes since the spectra showed no significant absorption due to free ligand, its hydrate or its perchlorate salt. The following analysis was obtained for the material whose spectrum is presented. (Found: $\mathrm{Li}, 1.34 ; \mathrm{C}, 60.7 ; \mathrm{H}, 4.12 ; \mathrm{N}, 10.4$. Calc. for $\mathrm{LiC}_{12} \mathrm{H}_{8} \mathrm{~N}_{2} \mathrm{ClO}_{4}: \mathrm{Li}, 2.41 ; \mathrm{C}, 50.4 ; \mathrm{H}$, $2 \cdot 79 ; \mathrm{N}, 9 \cdot 77$. Calc. for $\mathrm{Li}\left(\mathrm{C}_{12} \mathrm{H}_{8} \mathrm{~N}_{2}\right)_{2} \mathrm{ClO}_{4}: \mathrm{Li}, 1 \cdot 48 ; \mathrm{C}, 61 \cdot 7 ; \mathrm{H}, 3.42 ; \mathrm{N}, 12.0 \%$ ).

Bis-(1:10-phenanthroline)-sodium(I) perchlorate. Prepared according to the method of PFEIFFER and CHRISTELETा ${ }^{(13)}$ who report the air dried substance to be the trihydrate. In the present work, the air dried product suffered no loss in weight on drying in vacuo over $\mathrm{P}_{2} \mathrm{O}_{5}$ at $110^{\circ}$. Found: C, 59.4; $\mathrm{H}, 3.24 ; \mathrm{N}, 11 \cdot 7$. Calc. for $\left.\mathrm{Na}\left(\mathrm{C}_{12} \mathrm{H}_{8} \mathrm{~N}_{2}\right)_{2} \mathrm{ClO}_{4}: \mathrm{C}, 59 \cdot 7 ; \mathrm{H}, 3 \cdot 31, \mathrm{~N}, 11 \cdot 6 \%\right)$.

Tetra-(1:10-phenanthroline)-calcium(II) perchlorate trihydrate. A pure product could not be isolated according to the method in the literature. ${ }^{(13)}$ Since the infra-red spectrum closely resembled those of the other alkaline earth metals and showed no bands attributable to uncomplexed ligand, it has

\footnotetext{
* Carbon, hydrogen and nitrogen analyses were carried out by Spang Microanalytical Laboratories, Ann Arbor, Michigan.

(13) P. Pfeiffer and W. Christeleit, Z. Anorg. Chem. 239, 133 (1938).
} 
been included. The analysis suggests that the material is a mixture of the tris- and tetra-( $1: 10$ phenanthroline) calcium(II) perchlorates. (Found: $\mathrm{C}, 52.4 ; \mathrm{H}, 3.51 ; \mathrm{N}, 11.9 ; \mathrm{Ca}, 4.58 ; \mathrm{H}_{2} \mathrm{O}, 5.50$. Calc. for $\left.\mathrm{Ca}\left(\mathrm{C}_{22} \mathrm{H}_{8} \mathrm{~N}_{2}\right)_{4}\left(\mathrm{ClO}_{4}\right)_{2} \cdot 3 \mathrm{H}_{2} \mathrm{O}: \mathrm{C}, 56 \cdot 7 ; \mathrm{H}, 3 \cdot 74 ; \mathrm{N}, 11 \cdot 0 ; \mathrm{Ca}, 3.95 ; \mathrm{H}_{2} \mathrm{O}, 5 \cdot 32 \%\right)$.

Tetra-(1:10-phenanthroline)-strontium(II) perchlorate tetrahydrate. The method of PFEIFFER and Christeleit $^{(13)}$ was followed. (Found: $\mathrm{C}, 53.2 ; \mathrm{H}, 3.81 ; \mathrm{N}, 10.2 ; \mathrm{Sr}, 8.18 ; \mathrm{H}_{2} \mathrm{O}, 6.94$. Calc. for $\left.\mathrm{Sr}\left(\mathrm{C}_{12} \mathrm{H}_{8} \mathrm{~N}_{2}\right)_{4}\left(\mathrm{ClO}_{4}\right)_{2} \cdot 4 \mathrm{H}_{2} \mathrm{O}: \mathrm{C}, 53 \cdot 5 ; \mathrm{H}, 3 \cdot 71 ; \mathrm{N}, 10 \cdot 4 ; \mathrm{Sr}, 8 \cdot 11 ; \mathrm{H}_{2} \mathrm{O}, 6.67 \%\right)$.

Tetra-(1:10-phenanthroline)-barium(II) perchlorate tetrahydrate. The literature procedure ${ }^{(13)}$ was followed. (Found: $\mathrm{C}, 50.8 ; \mathrm{H}, 3.44 ; \mathrm{N}, 10.0 ; \mathrm{Ba}, 12.11 ; \mathrm{H}_{2} \mathrm{O}, 6.33$. Calc. for $\left.\mathrm{Ba}\left(\mathrm{C}_{12} \mathrm{H}_{8} \mathrm{~N}_{2}\right)_{4}\left(\mathrm{ClO}_{4}\right)_{2} \cdot 4 \mathrm{H}_{2} \mathrm{O}: \mathrm{C}, 51 \cdot 1 ; \mathrm{H}, 3.54 ; \mathrm{N}, 9 \cdot 92 ; \mathrm{Ba}, 12 \cdot 17 ; \mathrm{H}_{2} \mathrm{O}, 6 \cdot 38 \%\right)$.

Tetra-(1:10-phenanthroline)-manganese(II) perchlorate dihydrate. A solution of $0.17 \mathrm{~g}$ of $\mathrm{MnSO}_{4} \cdot \mathrm{H}_{2} \mathrm{O}$ and $0.60 \mathrm{~g}$ of the phenanthroline monohydrate in $100 \mathrm{ml}$ of hot water was treated with $0.25 \mathrm{~g}$ of sodium perchlorate. Colourless needles were obtained after recrystallization of the precipitate from water. (Found: $\mathrm{C}, 57.9 ; \mathrm{H}, 3.68 ; \mathrm{N}, 11.1 ; \mathrm{Mn}, 5.36 ; \mathrm{H}_{2} \mathrm{O}, 4.3$. Calc. for $\mathrm{Mn}\left(\mathrm{C}_{12} \mathrm{H}_{8} \mathrm{~N}_{2}\right)_{4}\left(\mathrm{ClO}_{4}\right)_{2} \cdot 2 \mathrm{H}_{2} \mathrm{O}: \mathrm{C}, 57 \cdot 1 ; \mathrm{H}, 3.56 ; \mathrm{N}, 11 \cdot 1 ; \mathrm{Mn}, 5 \cdot 43 ; \mathrm{H}_{2} \mathrm{O}, 3 \cdot 6 \%$.

Tris-(1:10-phenanthroline)-manganese(II) perchlorate. This compound was obtained as a pale yellow powder upon heating the tetra complex in vacuo at $185^{\circ}$ over $\mathrm{P}_{2} \mathrm{O}_{5}$. (Found: $\mathrm{C}, 54 \cdot 3 ; \mathrm{H}$, 3.24; $\mathrm{H}, 10 \cdot 6 ; \mathrm{Mn}, 6.81$. Calc. for $\mathrm{Mn}\left(\mathrm{C}_{12} \mathrm{H}_{8} \mathrm{~N}_{2}\right)_{3}\left(\mathrm{ClO}_{4}\right)_{2}$ : C, 54.4; $\left.\mathrm{H}, 3.04 ; \mathrm{N}, 10.6 ; \mathrm{Mn}, 6.91 \%\right)$.

Tris-(1:10-phenanthroline)-iron(II) perchlorate. Prepared by adding $0.30 \mathrm{~g}$ of sodium perchlorate to a solution of $0.39 \mathrm{~g} \mathrm{Fe}\left(\mathrm{NH}_{4}\right)_{2}\left(\mathrm{SO}_{4}\right)_{2} \cdot 6 \mathrm{H}_{2} \mathrm{O}$ and $0.60 \mathrm{~g}$ of the phenanthroline monohydrate in $50 \mathrm{ml}$ of hot water. Recrystallization of the amorphous product from hot water gave dark red crystals. (Found: C, 54.2; H, 3.10; N, 10.2. Calc. for $\mathrm{Fe}\left(\mathrm{C}_{12} \mathrm{H}_{8} \mathrm{~N}_{2}\right)_{3}\left(\mathrm{ClO}_{4}\right)_{2}$ : C, 54.4; H, 3.02; $\mathrm{N}, 10 \cdot 6 \%$.

Tris-(1:10-phenanthroline)-iron(III) perchlorate monohydrate. Chlorine gas was introduced into a solution of $0.30 \mathrm{~g}$ of $\mathrm{Fe}\left(\mathrm{NH}_{4}\right)_{2}\left(\mathrm{SO}_{4}\right)_{2} \cdot 6 \mathrm{H}_{2} \mathrm{O}, 0.60 \mathrm{~g}$ of phenanthroline monohydrate and $0.2 \mathrm{ml}$ of concentrated $\mathrm{H}_{2} \mathrm{SO}_{4}$ in $100 \mathrm{ml}$ of water until the colour changed from red to light blue. A moderate excess of $30 \% \mathrm{NaClO}_{4}$ solution was then added and the mixture cooled in an ice bath. The blue crystalline product was washed several times with small portions of cold water and dried in vacuo at room temperature over Dehydrite. If not protected from sunlight, the isolated product slowly turned red in colour. (Found: $\mathrm{C}, 45 \cdot 8 ; \mathrm{H}, 2 \cdot 86 ; \mathrm{N}, 9 \cdot 18 ; \mathrm{H}_{2} \mathrm{O}, 2 \cdot 10$. Calc. for $\mathrm{Fe}\left(\mathrm{C}_{12} \mathrm{H}_{8} \mathrm{~N}_{2}\right)_{3}\left(\mathrm{ClO}_{4}\right)_{3} \cdot \mathrm{H}_{2} \mathrm{O}$ : C, $47 \cdot 4 ; \mathrm{H}, 2 \cdot 85 ; \mathrm{N}, 9 \cdot 20 ; \mathrm{H}_{2} \mathrm{O}, 1.97 \%$.

Tris-(1:10-phenanthroline)-cobalt(II) perchlorate. A solution of $0.24 \mathrm{~g} \mathrm{of} \mathrm{CoCl}_{2} \cdot 6 \mathrm{H}_{2} \mathrm{O}$ in $20 \mathrm{ml}$ of ethanol was heated to boiling, treated successively with $0.60 \mathrm{~g}$ of phenanthroline monohydrate, $0.30 \mathrm{~g}$ of $\mathrm{NaClO}_{4}$ and $200 \mathrm{ml}$ of boiling water and then stored immediately in an evacuated desiccator. After $24 \mathrm{hr}$, the yellow-brown crystalline product was isolated, washed with small portions of water, and dried in vacuo at room temperature. (Found: $\mathrm{C}, 53.1 ; \mathrm{H}, 3.15 ; \mathrm{N}, 10.5$. Calc. for $\left.\mathrm{Co}\left(\mathrm{C}_{12} \mathrm{H}_{8} \mathrm{~N}_{2}\right)_{3}\left(\mathrm{ClO}_{4}\right)_{2}: \mathrm{C}, 54 \cdot 2 ; \mathrm{H}, 3.04 ; \mathrm{N}, 10 \cdot 5 \%\right)$.

Tris-(1:10-phenanthroline)-cobalt(III) perchlorate dihydrate. A solution of $0.24 \mathrm{~g}$ of $\mathrm{CoCl}_{2} \cdot 6 \mathrm{H}_{2} \mathrm{O}$, $0.60 \mathrm{~g}$ phenanthroline monohydrate, $2 \mathrm{ml}$ hydrogen peroxide ( 30 per cent) and $2 \mathrm{ml}$ concentrated $\mathrm{HCl}$ in $50 \mathrm{ml}$ distilled water was evaporated to approximately $5 \mathrm{ml}$. On treating the resulting syrupy mixture with $100 \mathrm{ml}$ of water followed by $1 \mathrm{ml}$ perchloric acid (72 per cent), a golden yellow precipitate formed. Recrystallized from $50 \mathrm{ml}$ of water containing $1 \mathrm{ml} \mathrm{30 \%} \mathrm{hydrogen} \mathrm{peroxide.} \mathrm{(Found:}$ C, 46.5; H, 3.06; N, 9.03; $\mathrm{H}_{2} \mathrm{O}, 4.06$. Calc. for $\mathrm{Co}\left(\mathrm{C}_{12} \mathrm{H}_{8} \mathrm{~N}_{2}\right)_{3}\left(\mathrm{ClO}_{4}\right)_{3} \cdot 2 \mathrm{H}_{2} \mathrm{O}: \mathrm{C}, 46 \cdot 4 ; \mathrm{H}, 3.00$; $\mathrm{N}, 9.00 ; \mathrm{H}_{2} \mathrm{O}, 3.86 \%$ ).

Tris-(1:10-phenanthroline)-nickel(II) perchlorate hemihydrate. Nickelous perchlorate was prepared in situ by treating $0.24 \mathrm{~g}$ of $\mathrm{NiCO}_{3}$ with excess perchloric acid followed by evaporation to near dryness. After dissolving in $50 \mathrm{ml}$ of water, the solution was treated with $1.2 \mathrm{~g}$ of phenanthroline monohydrate, heated for several minutes near boiling and then allowed to cool to room temperature. The resulting rose-red precipitate was recrystallized from water. (Found: C, 53.3; H, 3.18; N, 9.93; $\mathrm{H}_{2} \mathrm{O}, 1.08$. Calc. for $\mathrm{Ni}\left(\mathrm{C}_{12} \mathrm{H}_{8} \mathrm{~N}_{2}\right)_{3}\left(\mathrm{ClO}_{4}\right)_{2} \cdot \frac{1}{2} \mathrm{H}_{2} \mathrm{O}: \mathrm{C}, 53 \cdot 6 ; \mathrm{H}, 3 \cdot 10 ; \mathrm{N}, 10 \cdot 4 ; \mathrm{H}_{2} \mathrm{O}, 1 \cdot 11 \%$ ).

Bis-(1:10-phenanthroline)-copper(I) perchlorate. Prepared by adding a solution of $0.40 \mathrm{~g}$ phenanthroline monohydrate in $25 \mathrm{ml}$ ethanol to a boiling solution containing $0.25 \mathrm{~g} \mathrm{CuSO}_{4} \cdot 5 \mathrm{H}_{2} \mathrm{O}, 0.2 \mathrm{~g}$ hydroxylamine hydrochloride, $1 \mathrm{ml}$ conc. aqueous ammonia and $100 \mathrm{ml}$ of water. While still boiling, the solution was treated with a slight excess of $10 \% \mathrm{NaClO}_{4}$ solution and the dark violet precipitate produced was further digested for $1 \mathrm{hr}$ on the steam bath. The final product was washed well with water and dried at room temperature in vacuo over magnesium perchlorate. (Found: C, 55.3; $\mathrm{H}, 3 \cdot 27 ; \mathrm{N}, 10 \cdot 7 ; \mathrm{Cu}, 12 \cdot 22$. Calc. for $\mathrm{Cu}\left(\mathrm{C}_{12} \mathrm{H}_{8} \mathrm{~N}_{2}\right)_{2} \mathrm{ClO}_{4}: \mathrm{C}, 55 \cdot 2 ; \mathrm{H}, 3 \cdot 08 ; \mathrm{N}, 10 \cdot 7 ; \mathrm{Cu}, 12 \cdot 14 \%$ ). 
Bis-(1:10-phenanthroline)-copper(II) perchlorate. Cupric perchlorate was prepared in situ by dissolving $0.08 \mathrm{~g} \mathrm{CuO}$ in excess perchloric acid, evaporation to near dryness and dissolution in $100 \mathrm{ml}$ distilled water. After heating to near boiling, $0.50 \mathrm{~g}$ phenanthroline monohydrate were added to this solution and the resulting amorphous blue-green precipitate was digested seveial hours on a steam bath. The crystalline product obtained was recrystallized from $80 \mathrm{ml}$ of boiling methanol and dried in vacuo at room temperature. (Found: $\mathrm{C}, 46 \cdot 2 ; \mathrm{H}, 3 \cdot 15 ; \mathrm{N}, 9 \cdot 11 ; \mathrm{Cu}, 10 \cdot 16$. Calc. for $\left.\mathrm{Cu}\left(\mathrm{C}_{12} \mathrm{H}_{8} \mathrm{~N}_{2}\right)_{2}\left(\mathrm{ClO}_{4}\right)_{2}: \mathrm{C}, 46 \cdot 2 ; \mathrm{H}, 2 \cdot 56 ; \mathrm{N}, 9 \cdot 00 ; \mathrm{Cu}, 10 \cdot 19 \%\right)$.

Bis-(1:10-phenanthroline)-silver(I) perchlorate. Prepared by adding $0.13 \mathrm{~g} \mathrm{NaClO}_{4}$ to a solution of $0.17 \mathrm{~g} \mathrm{AgNO}_{3}$ and $0.60 \mathrm{~g}$ phenanthroline monohydrate dissolved in a mixture of $200 \mathrm{ml}$ water and $200 \mathrm{ml}$ methanol. The amorphous precipitate was digested $1 \mathrm{hr}$ on a steam bath, filtered and recrystallized twice from nitrobenzene. The pale yellow crystalline product was dried in vacuo at room temperature. (Found: $\mathrm{C}, 51 \cdot 2 ; \mathrm{H}, 2 \cdot 87 ; \mathrm{N}, 9.93 ; \mathrm{Ag}, 19 \cdot 2$. Calc. for $\mathrm{Ag}\left(\mathrm{C}_{12} \mathrm{H}_{8} \mathrm{~N}_{2}\right)_{2} \mathrm{ClO}_{4}$ : C, $50 \cdot 8 ; \mathrm{H}, 2 \cdot 82 ; \mathrm{N}, 9 \cdot 86 ; \mathrm{Ag}, 19 \cdot 0 \%)$.

Tris-(1:10-phenanthroline)-zinc(II) perchlorate. A zinc perchlorate solution was prepared by dissolving $0 \cdot 10 \mathrm{~g}$ zinc chloride in excess perchloric acid, evaporating nearly to dryness and redissolving in $200 \mathrm{ml}$ distilled water. This solution was heated nearly to boiling, $0.60 \mathrm{~g}$ phenanthroline monohydrate were added and the mixture allowed to cool and stand overnight. The crystalline product obtained was washed with small portions of cold water, dissolved in a small amount of hot water and allowed to crystallize slowly. The final product was in the form of glistening needles with a slight tinge of pink suggesting a trace of iron contamination. (Found: C, 53.8; H, 3.08; N, 10.6. Calc. for $\mathrm{Zn}\left(\mathrm{C}_{12} \mathrm{H}_{8} \mathrm{~N}_{2}\right)_{3}\left(\mathrm{ClO}_{4}\right)_{2}: \mathrm{C}, 53 \cdot 7 ; \mathrm{H}, 2 \cdot 98 ; \mathrm{N}, 10 \cdot 4 \%$ ).

Tris-(1:10-phenanthroline-cadmium(II) perchlorate. A cadmium perchlorate solution was prepared by dissolving $0.12 \mathrm{~g}$ of the metal in a mixture of $1 \mathrm{ml}$ conc. $\mathrm{HNO}_{3}$ and $1 \mathrm{ml} 72 \% \mathrm{HClO}_{4}$, evaporating to dryness, and redissolving in $200 \mathrm{ml}$ water. The complex was prepared in the same manner as the zinc complex. (Found: $\mathrm{C}, 50 \cdot 7 ; \mathrm{H}, 3 \cdot 11 ; \mathrm{N}, 9 \cdot 70$. Calc. for $\mathrm{Cd}\left(\mathrm{C}_{12} \mathrm{H}_{8} \mathrm{~N}_{2}\right)_{3}\left(\mathrm{ClO}_{4}\right)_{2}$ : $\mathrm{C}, 50 \cdot 7 ; \mathrm{H}, 2 \cdot 82 ; \mathrm{N}, 9 \cdot 85 \%$ ).

Tris-(1:10-phenanthroline)-mercury(II) perchlorate. This substance was obtained in the form of glistening white needles by following the procedure described for the zinc complex. (Found: $\mathrm{Hg}$, $21 \cdot 1 ; \mathrm{N}, 8 \cdot 76$. Calc. for $\left.\mathrm{Hg}\left(\mathrm{C}_{12} \mathrm{H}_{8} \mathrm{~N}_{2}\right)_{3}\left(\mathrm{ClO}_{4}\right)_{2}: \mathrm{Hg}, 21 \cdot 3 ; \mathrm{N}, 8.94 \%\right)$.

Bis-(1:10-phenanthroline)-thallium(I) perchlorate. Prepared according to the procedure of Pfeiffer and WerdelmanN. ${ }^{(14)}$ (Found: $\mathrm{C}, 43.5 ; \mathrm{H}, 2.41 ; \mathrm{N}, 8.77 ; \mathrm{Tl}, 30.0$. Calc. for $\left.\mathrm{Tl}\left(\mathrm{C}_{12} \mathrm{H}_{8} \mathrm{~N}_{2}\right)_{2} \mathrm{ClO}_{4}: \mathrm{C}, 43 \cdot 4 ; \mathrm{H}, 2 \cdot 41 ; \mathrm{N}, 8 \cdot 44 ; \mathrm{Tl}, 30 \cdot 6 \%\right)$.

Tetra-(1:10-phenanthroline)-lead(II) perchlorate. Prepared by the method of PFEIFFER and Christeletr. ${ }^{(13)}$ (Found: $\mathrm{Pb}, 18.5 ; \mathrm{N}, 10.3$. Calc. for $\mathrm{Pb}\left(\mathrm{C}_{12} \mathrm{H}_{8} \mathrm{~N}_{2}\right)_{4}\left(\mathrm{ClO}_{4}\right)_{2}: \mathrm{Pb}, 18.4 ; \mathrm{N}, 9.95 \%$ ).

Bis-(1:10-phenanthroline)-lead(II) perchlorate. Prepared by heating the tetra-lead complex in vacuo at $185^{\circ}$. The loss in weight corresponded to two moles of phenanthroline per mole of starting complex. (Found: $\mathrm{Pb}, 26 \cdot 9 ; \mathrm{N}, 7 \cdot 10$. Calc. for $\mathrm{Pb}\left(\mathrm{C}_{12} \mathrm{H}_{8} \mathrm{~N}_{2}\right)_{2}\left(\mathrm{ClO}_{4}\right)_{2}: \mathrm{Pb}, 27 \cdot 0 ; \mathrm{N}, 7 \cdot 30 \%$ ).

Tris-(1:10-phenanthroline)-bismuth(III) perchlorate. Prepared by the method of PFEIFFER and CHRISTELEIT. ${ }^{(13)}$ A colourless crystalline product was obtained after two recrystallizations from 1 per cent acetic acid. (Found: $\mathrm{Bi}, 19 \cdot 3 ; \mathrm{N}, 8 \cdot 20$. Calc for $\mathrm{Bi}\left(\mathrm{C}_{12} \mathrm{H}_{8} \mathrm{~N}_{2}\right)_{3}\left(\mathrm{ClO}_{4}\right)_{3}: \mathrm{Bi}, 19 \cdot 9 ; \mathrm{N}, 8.02 \%$ ).

Tris-(1:10-phenanthroline)-tin(II) perchlorate. Preparation of this compound was attempted by the method reported in the literature ${ }^{(14)}$ and various modifications. In all cases, the spectral results showed that no co-ordination to the metal had occurred and that the phenanthroline was present only as the perchlorate.

Tris-(2:2'-bipyridine)-iron(II) perchlorate, tris-(2:2'-bipyridine)-iron(III) perchlorate trihydrate, tris-(2:2'-bipyridine)-cobalt(II) perchlorate, tris-(2:2'-bipyridine)-cobalt(III) perchlorate trihydrate and tris-(2-2'-bipyridine)-nickel(II) perchlorate. These complexes were prepared according to the procedures given by BURSTALL and NYHOLM, ${ }^{(15)}$ and their compositions confirmed by analysis.

Tris-(2:2'-bipyridine)-manganese(II) perchlorate. Prepared by adding a solution of $0.62 \mathrm{~g}$ bipyridine in $5 \mathrm{ml}$ methanol to a solution of $0.17 \mathrm{~g} \mathrm{MnSO}_{4} \cdot \mathrm{H}_{2} \mathrm{O}$ in $100 \mathrm{ml}$ distilled water. The mixture was heated to effect solution, an excess of solid $\mathrm{NaClO}_{4}$ added and the precipitate isolated after cooling to room temperature. Recrystallization from hot water yielded a bright yellow crystalline product. (Found: $\mathrm{C}, 50 \cdot 1 ; \mathrm{H}, 3.44 ; \mathrm{N}, 11.7$. Calc. for $\mathrm{Mn}\left(\mathrm{C}_{10} \mathrm{H}_{8} \mathrm{~N}_{2}\right)_{3}\left(\mathrm{ClO}_{4}\right)_{2}: \mathrm{C}, 49 \cdot 9 ; \mathrm{H}, 3.32$; $\mathrm{N}, 11 \cdot 6 \%$ ).

(11) P. Pfeiffer and Br. Werdelmann, Z. Anorg. Chem. 261, 197 (1950).

(15) F. H. Burstall and R. S. Nyholm, J. Chem. Soc. $3570(1952)$. 